\title{
Influence of photoperiod and sex on locomotor behavior of meadow voles (Microtus pennsy(vanicus) in an automated light-dark 'anxiety' test
}

\author{
Klaus-Peter Ossenkopp ${ }^{a, b, *}$, Sari M. van Anders ${ }^{b}$, \\ Christopher G. Engeland ${ }^{a, b}$, Martin Kavaliers ${ }^{a, b}$
}

\author{
${ }^{a}$ Neuroscience Graduate Program, University of Western Ontario, London, Ont., Canada N6A 5C2 \\ ${ }^{\mathrm{b}}$ Department of Psychology, University of Western Ontario, London, Ont., Canada N6A 5C2
}

Received 14 June 2004; received in revised form 18 April 2005; accepted 2 May 2005

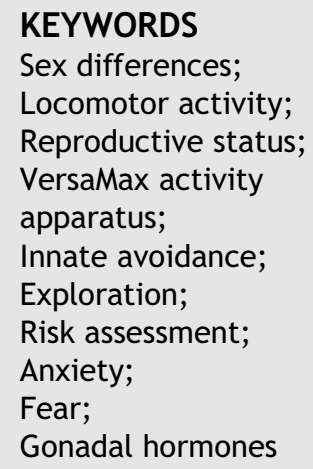

\begin{abstract}
Summary This study examined the influence of photoperiod on affective behavior (anxiety) of adult male and female meadow voles (Microtus pennsylvanicus), maintained in either a long or short day photoperiod, when tested in an automated (VersaMax) light-dark test. The light-dark test is based on an innate aversion of rodents to novel, brightly illuminated spaces and has been used with laboratory raised species, such as mice, to assess anxiety and/or fear related behaviors. Male and female meadow voles, housed either in a long day (LD: $16 \mathrm{~h}$ light) or short day (SD: $8 \mathrm{~h}$ light) photoperiod, were tested in the light-dark apparatus for 30 min on 3 consecutive days. All animals spent significantly $(p<0.001)$ less time in the brightly lit chamber (900 lux) than in the dark chamber. LD voles, especially females, spent significantly less time in the brightly lit area than did SD voles. Both horizontal and vertical movements occurred less frequently per unit time in the dark area relative to the light, but only in the LD voles. LD female voles were the least active group in the dark area on the first test day but the most active group in the light area, despite spending the least amount of time in this area on the second and third test days. The present results show that LD voles exhibit more anxiety related behaviors in this test situation than do SD voles. LD females avoided the brightly lit area the most, particularly when the apparatus was novel. Thus, both photoperiod and sex influence situation-based anxiety in this species. These findings suggest that meadow voles are an excellent animal model in which to examine the role of gonadal hormones, and their modulation of defence related neural systems, in the induction of anxiety.

(c) 2005 Elsevier Ltd. All rights reserved.
\end{abstract}

\footnotetext{
* Corresponding author. Address: Department of Psychology, Neuroscience Program, University of Western Ontario, London, Ont., Canada N6A 5C2. Tel.: +1 15196612111 82066; fax: +1 5196613961.

E-mail address: ossenkop@uwo.ca (K.-P. Ossenkopp).
} 


\section{Introduction}

Novel environments are generally aversive to small rodents as they tend to escape from such situations instead of exploring them (Misslin et al., 1989). Thus, it has been assumed that exposure to novel environments tends to elicit fear and/or anxiety in rodents and a variety of exploratory behavior models of anxiety have been based on this approach (Crawley, 1985). Previous studies have found that brightly lit open-field situations are aversive and induce emotional reactivity in a variety of rodents (see Walsh and Cummins, 1976 for review) and this tendency to avoid brightly lit open areas has been incorporated into the light-dark anxiety test (Crawley, 1981; Crawley and Goodwin, 1980). This test implicitly assumes that a preference of rodents, for the protected or dark area, rests on some mechanism of 'risk assessment' for the likelihood of potential predatory attack (Hendrie et al., 1997). Subsequently, this test has been used to pharmacologically characterize 'anxiety' in mice (Blumstein and Crawley, 1983; Costall et al., 1989; Crawley, 1981; Hascoët and Bourin, 1998) and rats (Bilkei-Gorzo et al., 1998; McQuade et al., 1999).

Although a variety of previous studies have found some sex differences in reactions to novel environments as well as other tests that have been used to examine anxiety in rodents (Bales et al., 2004; Imhof et al., 1993; Johnston and File, 1991; Nasello et al., 1998; Walsh and Cummins, 1976; Zimmerberg and Farley, 1993), most previous studies have tended to use only males in examining anxiety in rodents (Palanza, 2001). This lack of consideration of females has often been attributed to the fluctuations in anxiety associated with the estrous cycle (Palanza, 2001).

Animals living in non-tropical environments which show seasonal changes, exhibit a variety of alterations in physiology and behavior across the year. Many behaviors in these animals are regulated by the seasonal changes in the light cycle and facilitate adaptation to a variety of cyclical changes in the physical and social features of the environment (Prendergast et al., 2002). Meadow voles (Microtus pennsylvanicus) are a seasonally breeding, promiscuous species for which photoperiod represents the main cue to seasonal change. A long photoperiod is reproductively stimulatory and body weight, testes weight and testosterone levels are increased in male meadow voles, while the reverse occurs during a reproductively inhibitory short photoperiod
(Adams et al., 1980; Perrot-Sinal et al., 2000). As well, female meadow voles are induced ovulators and ovary weights and progesterone and estrogen levels increase only in a long photoperiod after pairing the females with a male (Cohen-Parsons and Carter, 1987, 1988; Lee et al., 1970; Perrot-Sinal et al., 2000; Seabloom, 1985). Thus, manipulation of the photoperiod allows for the induction of differential breeding states and hormone levels in this species.

Meadow voles previously have been found to exhibit sex differences in their behavior in an automated open-field situation (Perrot-Sinal et al., 1996, 2000) which was modulated by breeding status of the animals (Perrot-Sinal et al., 1998, 2000). In general, females exhibited greater avoidance of the center area of the openfield apparatus and lower levels of locomotor activity in this area, behavior indicative of increased anxiety. As well, male meadow voles increased the amount of time spent in the center area of the open-field as the test session progressed, whereas female voles did not (Perrot-Sinal et al., 1996). Thus, male voles changed their behavior from thigmotaxis (indicative of anxiety; Ossenkopp et al., 1994; Treit, 1985; Treit and Fundytus, 1989) at the start of the test session to exploration of the center area (reduced anxiety) by the end of the session. In a previous study of anxiety related behavior in voles, Hendrie et al. (1997) tested both male and female Microtus socialis in a light-dark apparatus but sex differences in behavior were not statistically examined. Examination of anxiety related behaviors in an elevated plus maze test with prairie voles (Bales et al., 2004) showed that females explored the open arms of the maze significantly less than did males, suggesting greater anxiety levels in the females.

The present study examined the hypothesis that photoperiod influences the affective behavior of meadow voles (Microtus pennsylvanicus) in a sexually dimorphic manner when exposed to a novel automated light-dark anxiety test situation. Male and female meadow voles were housed either under a long day photoperiod (LD) in mixed sex pairs or under a short day photoperiod (SD) in same sex pairs. The light dark 'anxiety' test was conducted in automated VersaMax activity monitors (Ossenkopp and Kavaliers, 1996) converted to contain two equally sized chambers, one being brightly lit and the other dark, to which the test animal had continuous access. The test situation was either novel (first test day) or non-novel (second and third test days). 


\section{Materials and methods}

\subsection{Subjects}

Thirty-two male and 32 female laboratory bred (5-6 generations removed from wild) naïve adult meadow voles $(27-65 \mathrm{~g})$ were used as subjects. The animals were housed in polypropylene cages with hardwood bedding (Beta Chip) and maintained in a colony room at $21 \pm 1^{\circ} \mathrm{C}$. All animals were given free access to food (Agway lab chow) and tap water. The photoperiod in the colony room was either a LD (i.e. reproductively stimulatory; L:D 16:8, lights on 06:00 to $22: 00 \mathrm{~h}$ ) or a SD (i.e. reproductively inhibitory; L:D 8:16, lights on 10:00 to $18: 00 \mathrm{~h}$ ) for a minimum of 6 weeks prior to testing. The colony room L:D cycles were in phase with the environmental lighting cycle and all testing was performed during the light phase at midday. All procedures used were carried out in compliance with the Canadian Council on Animal Care guidelines.

\subsection{Light-dark test situation}

\subsubsection{Automated activity monitoring system}

Behavioral data were collected using eight VersaMax Animal Activity Monitors (AccuScan Model RXYZCM16, Columbus, $\mathrm{OH}$ ). Each chamber was $40 \times 40 \times$ $30.5 \mathrm{~cm}^{3}$, made of clear Plexiglas and covered with a Plexiglas lid with air-holes. Infrared monitoring sensors were located every $2.54 \mathrm{~cm}$ along the perimeter (16 infrared beams along each side) and $2.5 \mathrm{~cm}$ above the floor. Two additional sets of 16 sensors were located $8.0 \mathrm{~cm}$ above the floor on opposite sides. Data were collected and anlayzed by a VersaMax Analyzer (AccuScan Model CDA-8, Columbus, $\mathrm{OH}$ ) which in turn sent information to an IBM computer where it was stored for future analyses. Three fluorescent light tubes were located above each chamber and provided the light source (approximately 900 lux at the floor of the light chambers).

A black Plexiglas 'dark' box $\left(40 \times 20 \times 20 \mathrm{~cm}^{3}\right.$ with an opaque top) fit inside each larger activity monitor and took up half of the floor space in the activity chamber. The dark box had small holes located in its sides to allow the infrared beams to pass uninterrupted across the box and also had a $13 \times 5 \mathrm{~cm}^{2}$ opening in the middle of the front wall as a doorway for the animals.

\subsection{Behavioral variables}

\subsubsection{Chamber choice related variables}

As the animals explored the two chambers in the light-dark apparatus, the automated monitoring system quantified the latency (s) to enter the dark box when first place in the apparatus, the amount of time (s) spent in the light (or dark) chamber, and the number of transitions made between the two compartments.

\subsubsection{Activity related variables}

During each test session the following activity variables were quantified in the light and the dark areas of the apparatus: horizontal activity; number of beam breaks in the lower infrared sensors per unit time in the light and dark area, respectively; horizontal movement time; time spent moving as a proportion of time spent in the light and dark area, respectively; vertical activity; number of beam breaks in the upper infrared sensors per unit time in the light and dark area, respectively; and vertical time; time spent activating the upper set of beams per unit time in the light and dark area, respectively.

\subsection{Experimental procedures}

\subsubsection{Photoperiod manipulation}

LD (16:8 h L:D) voles were maintained under a reproductively stimulatory photoperiod which has been shown to increase testosterone levels and testes weight in males (Adams et al., 1980; PerrotSinal et al., 2000). Three to four days prior to testing LD voles were paired with a vole of the opposite sex (one pair per cage) to ensure a state of elevated sex hormone levels in females (CohenParsons and Carter, 1987, 1988; Galea et al., 1995; Perrot-Sinal et al., 2000). It has been shown that a $72 \mathrm{~h}$ exposure to males is maximally effective at inducing estrous in female voles (Seabloom, 1985). On the first test day it was confirmed that all males had testes that were fully descended (i.e. scrotal) indicating increased reproductive activity (McCravy and Rose, 1992). All females were monitored for 20 days (gestation period) following the last test day for pregnancy. Six females were subsequently found to be pregnant and the data from these pairs were removed from the data set. Data from 16 male and 16 female meadow voles, tested under the LD condition, were used in the analysis.

SD (8:16 h L:D) voles were maintained under a reproductively inhibitory photoperiod. Three to four days prior to testing short-day voles were paired with a vole of the same sex (one pair per cage). Same sex pairs were used to minimize aggressive interactions. On the first test day it was confirmed that all males had testes in the lower abdomen (i.e. regressed), indicative of low reproductive activity (McCravy and Rose, 1992). Data from 16 male and 16 
female meadow voles, tested under the SD condition, were used in the analysis.

Previous data from our laboratory (Perrot-Sinal et al., 2000) had confirmed that these type of photoperiod and housing manipulations resulted in the appropriate significant elevations of estradiol levels in the LD female voles and testosterone in the LD male voles, relative to the respective SD voles.

\subsubsection{Light-dark testing procedure}

Voles were tested on three consecutive days. Pairs housed together were tested at the same time but placed individually in a different test box. They were placed into the light chamber and their behavior in the light-dark test apparatus was automatically monitored for $30 \mathrm{~min}$ at the same time on each day (Ossenkopp and Mazmanian, 1985). All test chambers were cleaned after each test period with a commercial detergent (Alconox) and rinsed with a baking powder solution to eliminate any residual odors.

\subsection{Statistical analyses}

All data were analyzed with the Statistical Package for the Social Sciences (SPSS) for Windows, version 9.0. All activity variables were corrected for total time spent in the relevant compartment (e.g. number of beam breaks per sec in the light compartment). A mixed design (split-plot) analysis of variance (ANOVA) was used to examine the effects of the between subject factors of sex ( 2 levels) and photoperiod ( 2 levels) and the within subject factor of test day ( 3 levels). The criterion used for significance was $\alpha=0.05$ and Greenhouse$G$ Gisser corrected $F$-values were used to determine significance in the ANOVA procedures. Post-hoc comparisons consisted of Tukey's HSD test.

\section{Results}

\subsection{Chamber choice related variables}

All voles spent significantly more time in the dark area than in the brightly lit area $(F(1,59)=112.08$, $p<0.001$; Fig. 1 and note that equal time in each compartment was $900 \mathrm{~s}$ ) and in general LD voles spent significantly more time in the dark than $S D$ voles (photoperiod main effect, $F(1,59)=5.58$, $p=0.021$ ). There was also a significant day by photoperiod interaction $(F(2,188)=4.21$, $p=0.045$ ).

Examination, with post-hoc pair-wise contrasts, of the time spent in the brightly lit area on the first

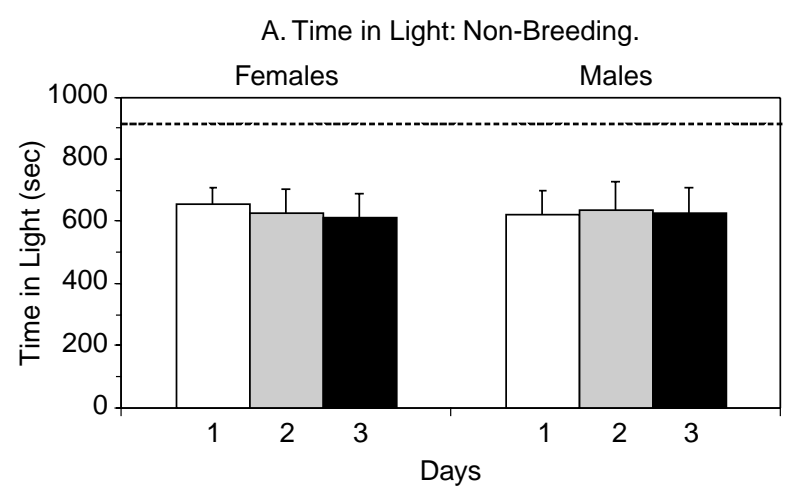

B. Time in Light: Breeding.

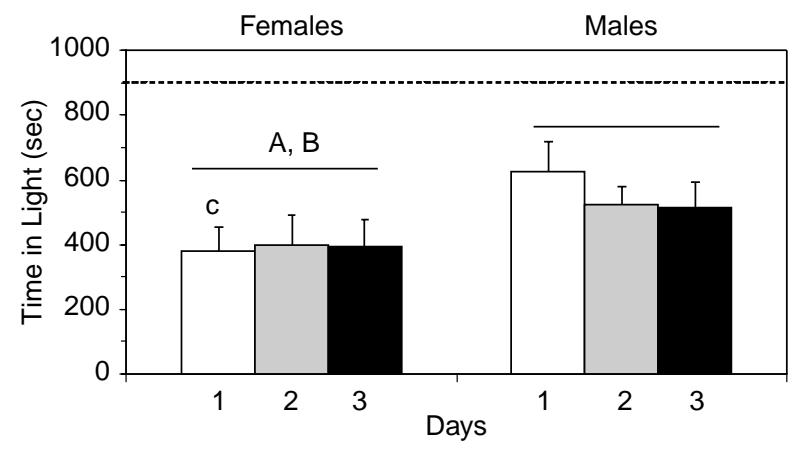

Figure 1 Group mean time spent in the light chamber for female and male SD (non-breeding) and LD (breeding) meadow voles over 3 days of testing. The dashed line represents the equal choice level for the two chambers (900 s). The error bars are SEM. ' $A$ ' indicates a significant sex difference (over test days) for LD (breeding) voles. 'B' indicates a significant photoperiod difference (over test days) for female voles. ' $C$ ' indicates that LD (breeding) females are significantly different from SD (non-breeding) females and all males on the novel test day 1 .

(novel) test day revealed that LD females spent significantly less time in the light than SD females $(p<0.01)$ and significantly less time than both LD $(p<0.01)$ and SD $(p<0.05)$ males. Post-hoc pairwise comparisons on the non-novel test days (second and third test days) revealed no significant differences among the groups for either day.

There were no significant main effects or interactions among groups for the number of chamber transitions measure (Fig. 2), nor for the latency data (not shown).

\subsection{Activity related variables}

In general voles exhibited less horizontal activity (Fig. 3), horizontal movement time (Fig. 4), vertical activity (Fig. 5) and vertical time (Fig. 6) in the dark chamber than in the light chamber (Chamber main effects; $F(1,59) \geq 67.44, p<0.001)$. There were also significant interactions of photoperiod with chamber type for all four activity measures 


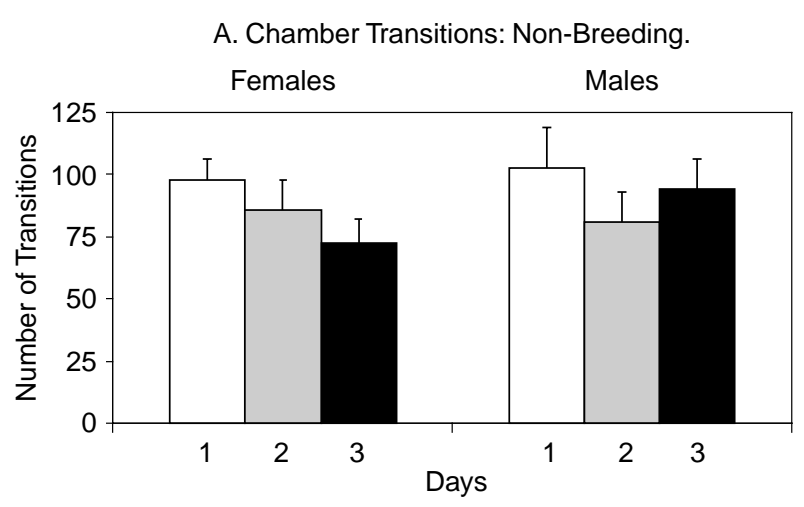

B. Chamber Transitions: Breeding.

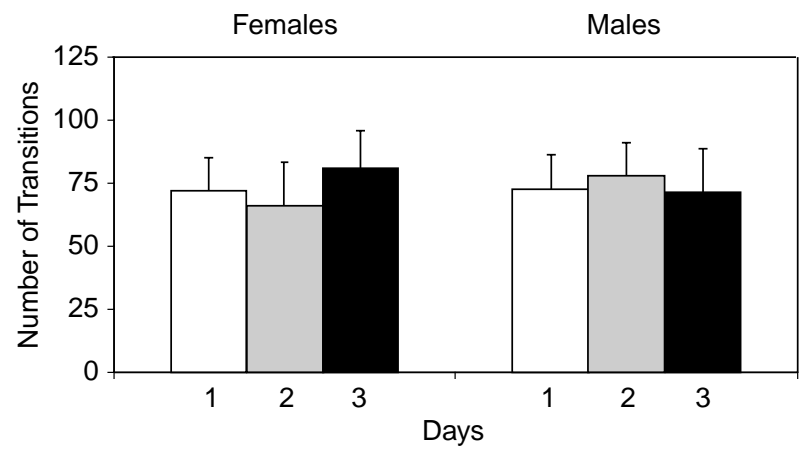

Figure 2 Group mean number of transition movements (from one chamber to the other) for female and male, SD (non-breeding) and LD (breeding) meadow voles over 3 days of testing. Error bars are SEM.

$(F(1,59) \geq 5.65$, ps $<0.021)$ indicating significantly less activity in the dark chamber relative to the light chamber for LD voles, but not for SD voles (Figs. 3-6).

Examination of the various activity variables in the light and dark chambers indicated the following significant differences on the first (novel) test day; LD females showed significantly less dark horizontal activity (Fig. 3$)$ than SD females $(p<0.05)$ and SD males $(p<0.05)$, and less dark horizontal movement time (Fig. 4$)$ than SD males $(p<0.05)$. LD males exhibited significantly more vertical activity in the light (Fig. 5) than SD females $(p<0.05)$. There was significantly less dark horizontal activity and horizontal movement time in both LD males and females, relative to all four groups in the light chamber ( $p s<0.01)$ and less horizontal activity and horizontal movement time in SD males and females in the dark relative to the light chamber $(\mathrm{ps}<0.05)$. Both LD and SD males and females showed less vertical activity and vertical time in the dark than all four groups in the light chamber ( $p s<0.01$ ).

Additional post-hoc comparisons on the nonnovel test days (second and third test days) revealed significant differences only for the horizontal movement variables (horizontal activity and movement time). All of the horizontal movements in the dark were significantly less than in the light on both the second and third test days ( $p s<0.05)$. In addition, horizontal movements in the light were significantly greater for LD females than for SD females and LD males ( $p s<0.01$ ) as well as SD males (ps $<0.05)$ on both days. No significant group differences were evident for any of the other measures on the non-novel test days.

\section{Discussion}

The fist major finding of this study was that meadow voles in all experimental conditions spent significantly less time in the brightly lit chamber than the dark chamber. Avoidance of the brightly lit chamber by the voles is in good agreement with previous data from laboratory mice (e.g. Bourin and Hascoët, 2003; Crawley, 1981; Crawley and Goodwin, 1980; Hascoët and Bourin, 1998), laboratory rats (Bilkei-Gorzo et al., 1998; McQuade et al., 1999), and a wild vole (Microtus socialis) species (Hendrie et al., 1997), and provides additional support for the generalized validity of the lightdark test as a measure of 'anxiety' in rodents. The brightly lit chamber is putatively an aversive situation because of a perception of an increased risk of detection by a predator (Hendrie et al., 1997), and this aversive situation elicits fear and/or anxiety in the voles. It is also interesting to note that rats exposed to sudden periods of darkness while in an open-field situation or in an elevated plus-maze exhibit increased activity levels and decreased levels of behaviors indicative of anxiety (Nasello et al., 1998), further supporting an anxiogenic effect of brightly lit open areas used in laboratory behavioral tests.

The present finding of increased time in the dark chamber is also consistent with the behavior of voles in the wild. Cover becomes an important factor with regard to isolating prey from some of their predators and it can affect risk of predation (Elton, 1939; Jacob and Hempel, 2003). Light intensity also affects the activity and habitat use by small mammals (Jacob and Brown, 2000; Kotler, 1984; Travers et al., 1988). Voles tend to remain under cover or under low levels of illumination (Dobly, 2001; Harestad and Shackleton, 1990) making occasional forays into the lighted areas. This then reinforces the ecological validity of the laboratory light-dark test.

The second major finding is that voles in a long day photoperiod are, in general, more 'anxious' than voles in a short day photoperiod as evidenced 

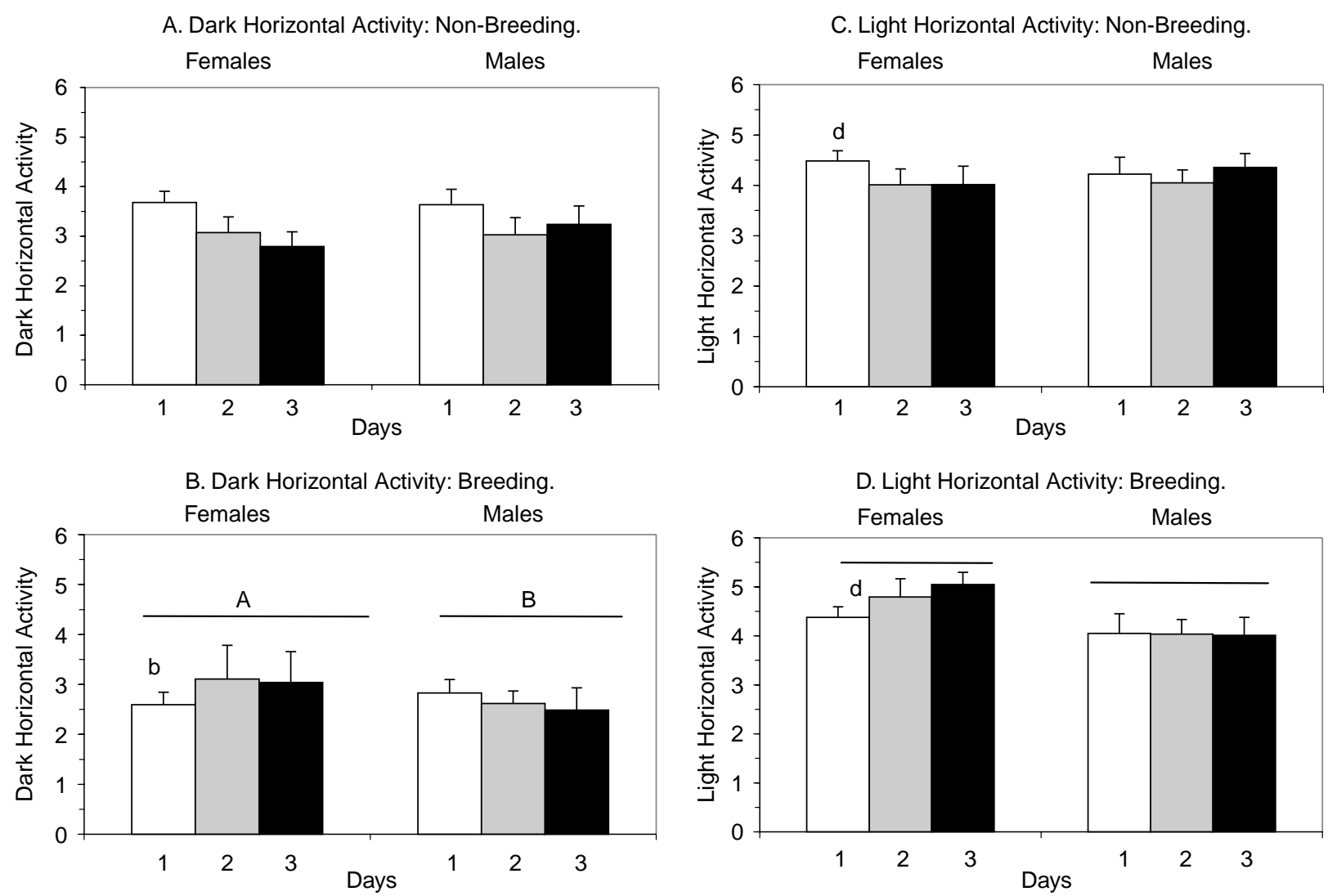

Figure 3 Group mean time corrected horizontal activity (lower level beam breaks per sec in the chamber) in the dark chamber (panels $A$ and B) and in the light chamber (panels C and D) for female and male, SD (non-breeding) and LD (breeding) meadow voles over 3 days of testing. Error bars are SEM. 'A' indicates a significant light/dark chamber difference for females over days of testing. ' $B$ ' indicates a significant light/dark chamber difference for males over days of testing. ' $b$ ' indicates a significant photoperiod difference for females on the novel test day 1 in the dark compartment. 'd' indicates a significant light/dark chamber difference for females on day 1.

by greater avoidance of the brightly lit chamber. These data are consistent with previous observations that photoperiod, and associated changes in breeding status, influence the behavioral reactions, including affective behaviors, of meadow voles to a predator odor and other aversive stimuli. In microtine rodents, exposure to predator odor is often used to simulate predation risk. If the situational risk assessment is influenced by exposure to a predator odor and this results in increased anxiety, then the findings that male LD breeding voles, briefly exposed to a fox odor, subsequently exhibit greater reductions of activity in an open-field test than do SD nonbreeding males (Perrot-Sinal et al., 2000), is at least partially consistent with the present observations. Although LD breeding female voles initially showed only a small decrease in activity in response to the predator odor they displayed increased reductions in open-field activity with repeated exposure to fox odor (Perrot-Sinal et al., 1999).
Comparison of the influence of photoperiod altered breeding status on anxiety levels in meadow voles to studies on breeding status and anxiety in other rodent species, provides conflicting evidence. A number of studies have examined the effects of the estrous cycle in rats and mice on various tests of anxiety (Frye et al., 2000; Marcondes et al., 2001; Mora et al., 1996; Morgan et al., 2004; Palanza, 2001). Under low light intensities exploration of the open arms of an elevated plus-maze by rats was greater in proestrus (greater sexual receptivity) and estrus (Frye et al., 2000; Marcondes et al., 2001; Mora et al., 1996) than during diestrus, suggesting that rats are less anxious in proestrus than in diestrus. In general increased estrogen and progesterone levels tend to be associated with decreased fear of the open arms in the elevated plus-maze test with rats (Mora et al., 1996; Morgan et al., 2004).

The estrous cycle did not influence anxiety related behaviors in CD-1 mice as indexed by 


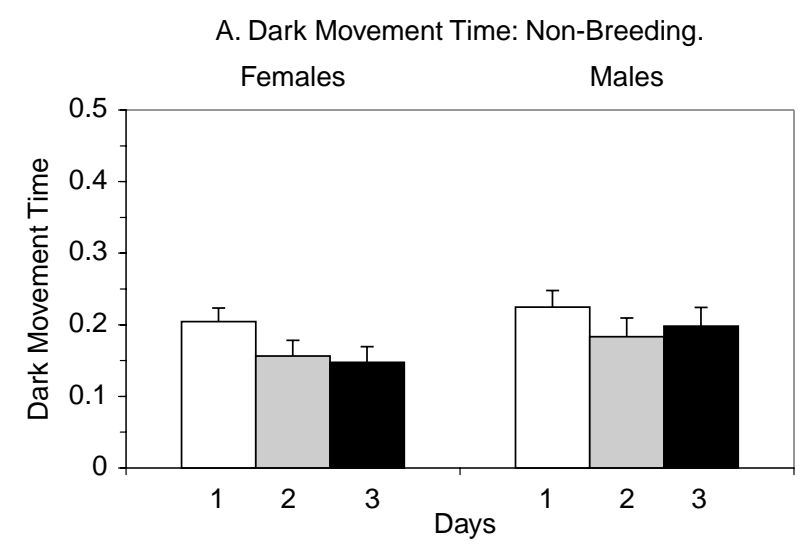

B. Dark Movement Time: Breeding.

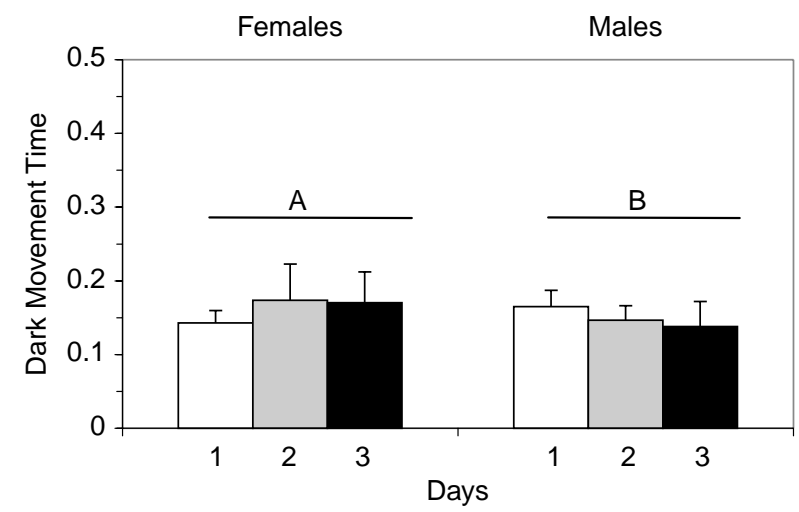

C. Light Movement Time: Non-Breeding.

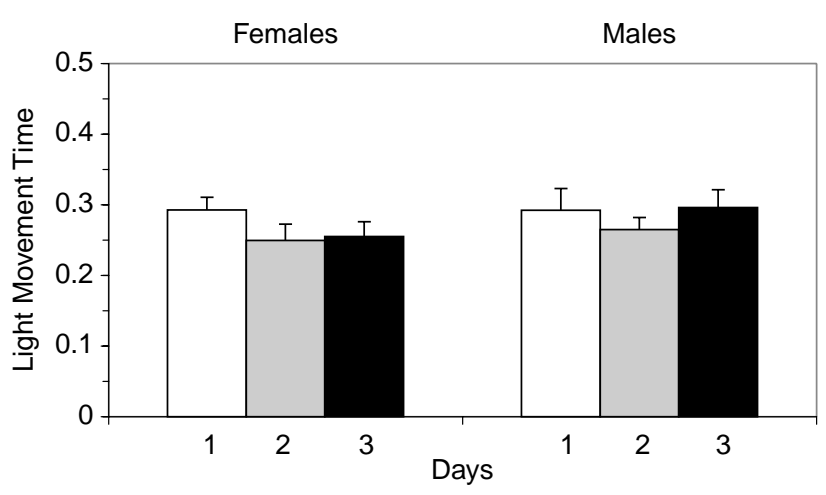

D. Light Movement Time: Breeding.

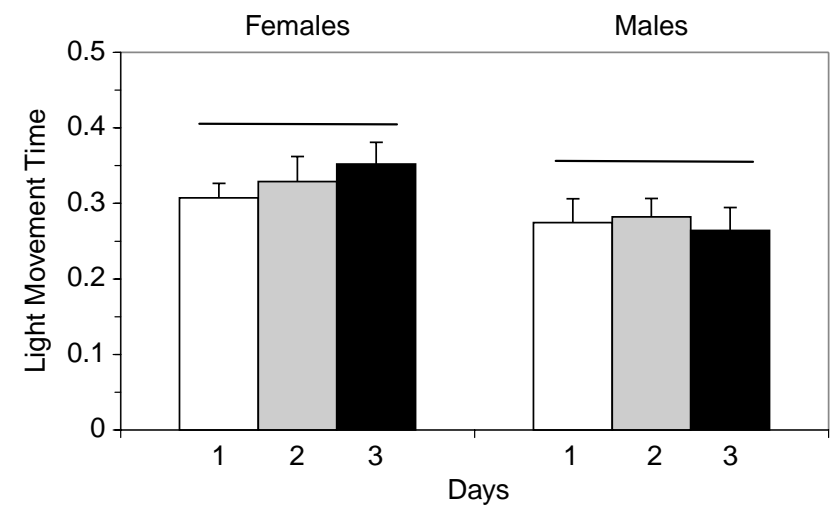

Figure 4 Group mean time corrected movement time (sec of horizontal movement per sec in the chamber) in the dark chamber (panels A and B) and in the light chamber (panels C and D) for female and male, SD (non-breeding) and LD (breeding) meadow voles over 3 days of testing. Error bars are SEM. ' $A$ ' indicates a significant light/dark chamber difference for females over days of testing. 'B' indicates a significant light/dark chamber difference for males over days of testing.

latency to enter an open-field from the home cage or by risk assessment behaviors (Palanza, 2001). However, both C57BL/6 and Swiss-Webster mice exhibited increased fear behavior in an open field and the elevated plus-maze test, under the influence of increased estradiol levels (Morgan and Pfaff, 2001, 2002).

Thus, the previous findings in rats contrast with the present observations in meadow voles. Less anxiety related behavior occurs in proestrus females rats whereas LD (breeding) meadow vole females exhibit more of these behaviors. The findings from the studies with mice are also not clear. These discrepancies may reflect species differences, perhaps related to the degree of normal nocturnal versus diurnal activity, and/or methodological differences across studies, but they could also reflect a greater level of domestication in laboratory rats and mice when compared to meadow voles which are only several generations removed from the wild. For example, Augustsson and Meyerson (2004) showed that wild house mice displayed greater avoidance of open areas (more thigmotaxic) in laboratory tests than did two laboratory strains (BALB/C and C57BL/6).

Another possibility relates to the finding that the nature of the activity rhythms of voles may change across seasons (photoperiods). Activity patterns shifted from predominantly nocturnal dominance in the summer to crepuscular or diurnal dominance in the winter when examined in running wheel tests (Rowsemitt, 1986). Thus, it is possible that such shifts could have modulated the current findings in the light-dark apparatus. Another issue to consider is the possibility that the decreased activity levels in the dark chamber in LD voles (Figs. 3 and 4) could represent increased sleep behaviors. As visual observation of behavior in the dark chamber was not possible, sleep behavior must be considered in interpreting increased dark chamber preference as an index of increased anxiety. Although it is unlikely that much sleep occurred in such short 30 min tests and there were few differences in dark activity levels between the two photoperiod conditions 
A. Dark Vertical Activity: Non-Breeding.

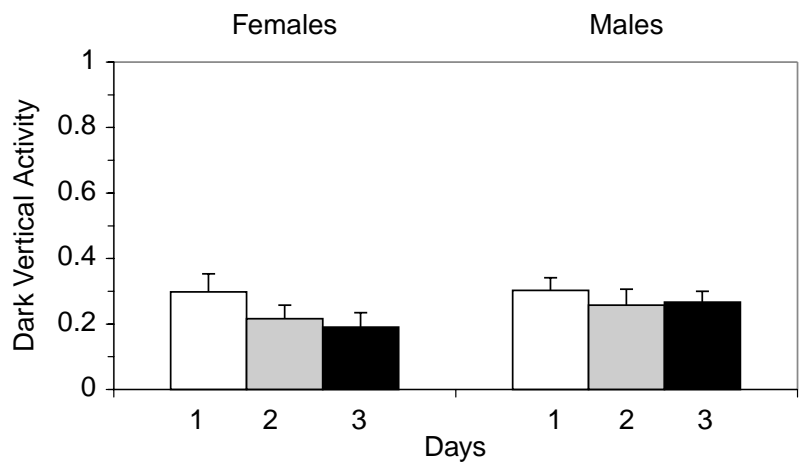

B. Dark Vertical Activity: Breeding.

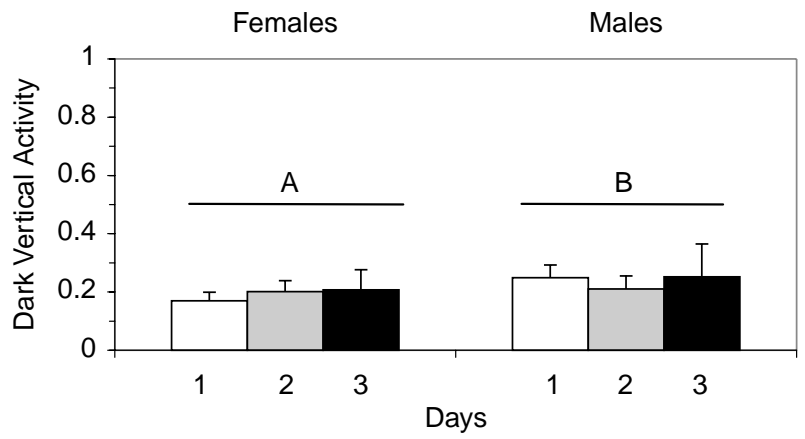

C. Light Vertical Activity: Non-Breeding.

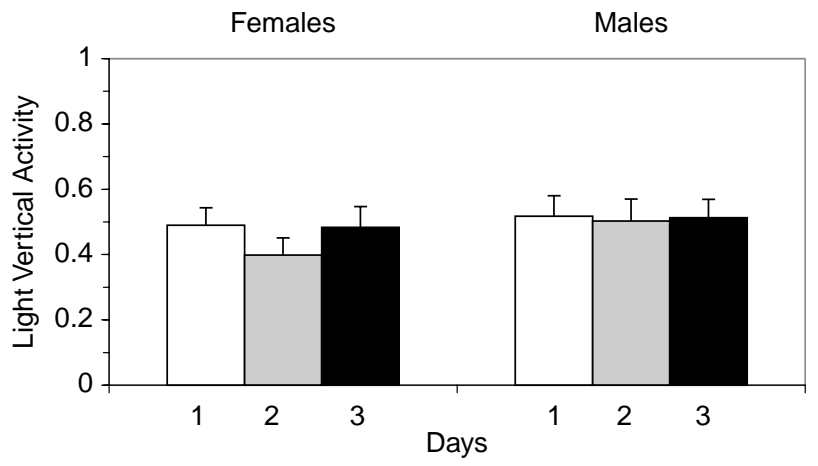

D. Light Vertical Activity: Breeding.

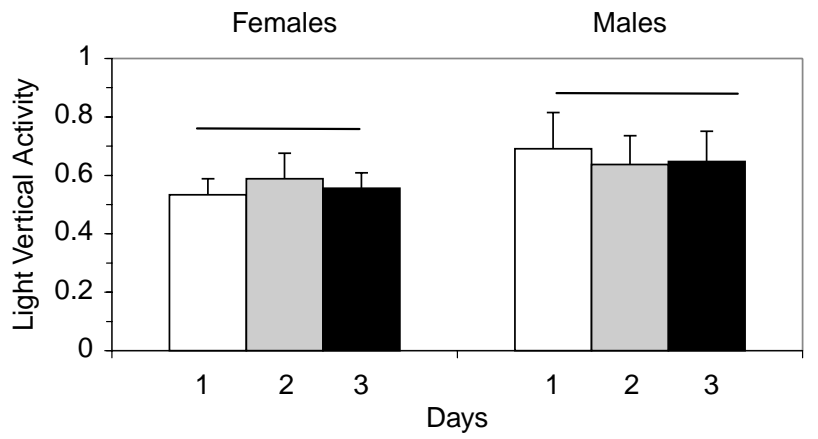

Figure 5 Group mean time corrected vertical activity (upper level beam breaks per sec in the chamber) in the dark chamber (panels $A$ and $B$ ) and the light chamber (panels $C$ and D) for female and male, SD (non-breeding) and LD (breeding) meadow voles over 3 days of testing. Error bars are SEM. 'A' indicates a significant light/dark chamber difference for females over days of testing. 'B' indicates a significant light/dark chamber difference for males over days of testing.

(Figs. 3-6), future studies should nevertheless examine this issue with low light video recording of behavior in the dark chamber. As well, given that the behavioral influence of gonadal hormones is dependent on photoperiod (e.g. Campbell et al., 1978; Turek et al., 1975), future studies also need to examine the relationship between differing levels of gonadal hormones and photoperiod effects by means of gonadectomy and hormone replacement manipulations.

Interesting sex differences were also obtained in the present study, especially on the first test day when the apparatus was novel for the animals. LD female meadow voles spent significantly less time in the light chamber than did LD males as well as both SD males and females. These differences suggest that female voles in a breeding state found the light chamber more aversive and were more anxious when in this part of the apparatus than any of the other groups of voles. Male voles did not show an equivalent difference between the two photoperiod conditions. In addition to these sex differences in chamber choice there also were interesting sex differences in activity levels in the apparatus. The LD females were the least active group in the Dark chamber when the apparatus was novel (day 1) but the most active group in the light chamber when the apparatus was non-novel (days 2 and 3 ).

The present findings show that the LD female voles were significantly more 'anxious' on the first test day relative to all of the other groups. They avoided the light area and were relatively inactive in the dark area. These findings are in agreement with previous data from our laboratory (Perrot-Sinal et al., 1996, 2000) showing that females are more thigmotaxic (an index of anxiety) in an open-field situation (Ossenkopp et al., 1994; Treit, 1985; Treit and Fundytus, 1989). Examination of anxiety related behaviors in the plus-maze test with prairie voles also demonstrated that female voles are more anxious than males (Bales et al., 2004). The females spent significantly less time in the open arms of the maze relative to the males. It should be noted that these prairie voles were housed under a long day light cycle (14:10 L:D), putatively inducing breeding conditions. Whether or not prairie voles would exhibit a similar sex 


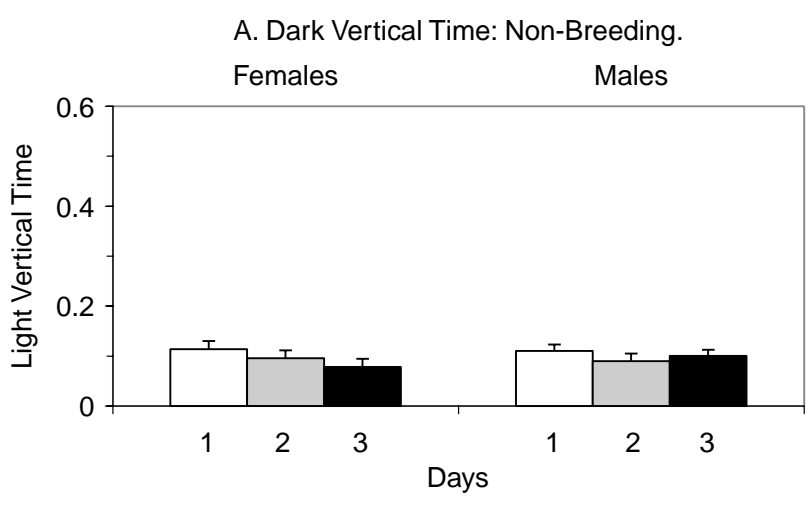

B. Dark Vertical Time: Breeding.

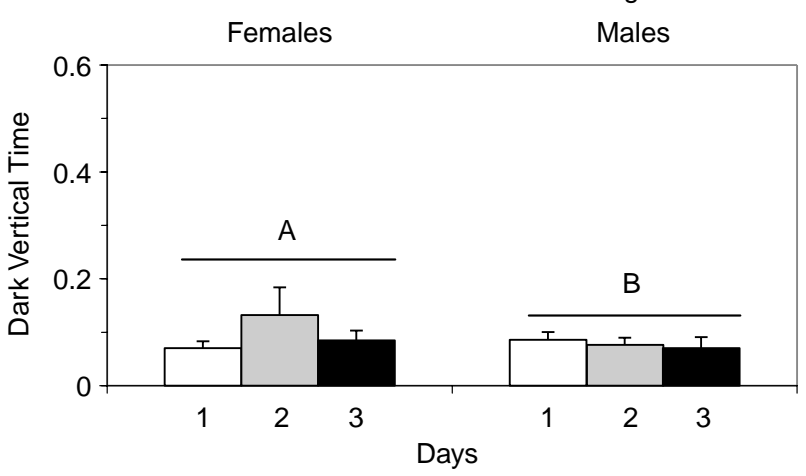

C. Light Vertical Time: Non-Breeding.

Females

Males

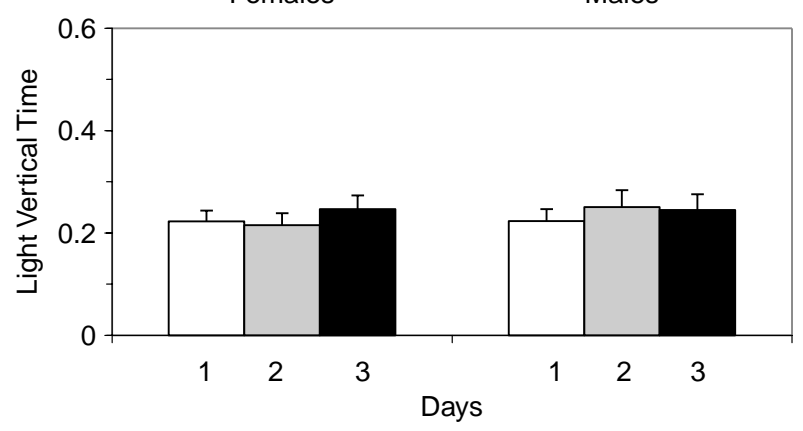

D. Light Vertical Time: Breeding.

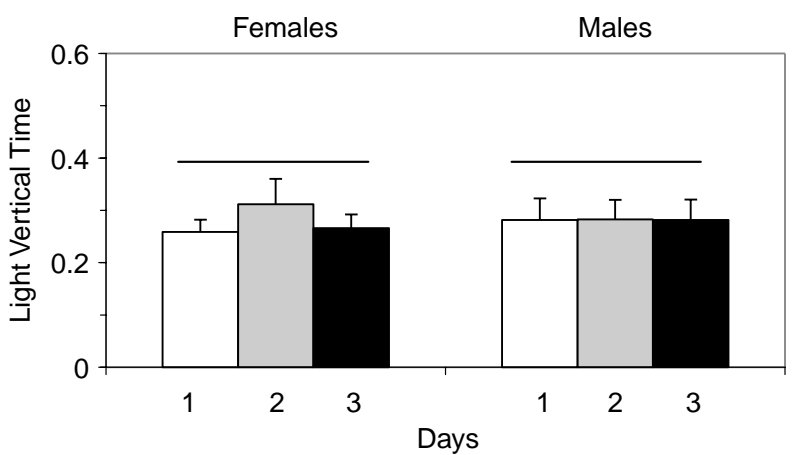

Figure 6 Group mean time corrected vertical time (sec of vertical movement per sec in the chamber) in the dark chamber (panels $A$ and $B$ ) and the light chamber (panels $C$ and D) for female and male, SD (non-breeding) and LD (breeding) meadow voles over 3 days of testing. ' $A$ ' indicates a significant light/dark chamber difference for females over days of testing. 'B' indicates a significant light/dark chamber difference for males over days of testing.

difference in anxiety related behaviors on the plusmaze test, when housed in a short day light cycle, remains to be determined.

The present observations are also consistent with previous data from laboratory rats and mice showing that females are more thigmotaxic in open-field tests (Archer, 1975; Morgan et al., 2004) and spend less time on the open arms of the plus-maze (e.g. Morgan and Pfaff, 2002). Although few data exist on rodent sex differences in the lightdark test (Bourin and Hascoët, 2003) there is one study which found that in grouped, but not singly housed Swiss-Kunming mice, females spent significantly more time in the dark chamber relative to males (Guo et al., 2004); findings which indicate that the group housed females were more anxious than the males. In contrast, Voikar et al. (2001) found few sex differences in the light-dark test with a variety of group housed mouse strains.

The fact that LD voles in the present study were housed in mixed-sex pairs and that this procedure may have influenced the level of stress in the female voles, is another factor to consider with respect to the present findings. Increased levels of stress could have resulted from males exhibiting aggressive behaviour toward the females prior to anxiety testing, potentially resulting in higher levels of anxiety related behaviors in LD females. As no measures of pre-test aggressive behaviour in the males were obtained, this possibility needs to be addressed in future studies. Clearly more research needs to be directed at the interesting question of sex differences in anxiety, as measured in the light-dark test, and the factors responsible for these differences.

The observations of the present study are in good agreement with the hypothesis that breeding females need to have a heightened sensitivity (e.g. increased vigilance while sniffing, scanning, or listening) to relevant environmental stimuli in order to optimize decisions concerning reproduction and related behaviors. These findings also suggest that gonadal hormones may modulate the neural systems responsible for defence against predators (Blanchard et al., 1991; Blanchard et al., 1992; Norrdahl and Korpimaki, 1998) and other dangers in the environment. It is also possible that disregulation of these same neural systems may be involved in the manifestation of anxiety and related disorders. Indeed, most anxiety disorders in 
humans tend to have a higher incidence in females, as compared to males (e.g. Pigott, 1999). There also are sex differences in the characteristics of some of the anxiety disorders, including differences in the putative etiological factors (Breslau et al., 1995; Pigott, 1999). The present study suggests that meadow voles may be an excellent animal model in which to examine the role of gonadal hormones, and their modulation of defence related neural systems involved in the induction of anxiety. This animal model may further be useful in examining potential pharmacotherapeutic approaches in treating various anxiety disorders.

\section{Acknowledgements}

This research and preparation of this manuscript were supported by Natural Sciences and Engineering Research Council of Canada (NSERC) operating and equipment grants to $M$. Kavaliers and K.-P. Ossenkopp. It was also made possible by equipment and software support from AccuScan Instruments (Columbus, OH). C.G. Engeland, who is now at the University of Illinois at Chicago, Department of Periodontics, was supported by an Ontario Graduate Scholarship and S.M. van Anders, who is now at Simon Fraser University, Department of Psychology, was supported by a NSERC of Canada USRA scholarship. We thank Shelley Cross-Mellor for technical assistance with the manuscript.

\section{References}

Adams, M.R., Tamarin, R.H., Callard, I.P., 1980. Seasonal changes in plasma androgen levels and the gonads of the beach vole, Microtus breweri. Gen. Comp. Endocrinol. 41, 31-40.

Archer, J., 1975. Rodent sex differences in emotional and related behavior. Behav. Biol. 14, 451-479.

Augustsson, H., Meyerson, B.J., 2004. Exploration and risk assessment: a comparative study of male house mice (Mus musculus musculus) and two laboratory strains. Physiol. Behav. 81, 685-698.

Bales, K.L., Pfeifer, L.A., Carter, C.S., 2004. Sex differences and developmental effects of manipulations of oxytocin on alloparenting and anxiety in prairie voles. Dev. Psychobiol. 44, 123-131.

Bilkei-Gorzo, A., Gyertyan, I., Levay, G., 1998. mCPP-induced anxiety in the light-dark box in rats-a new method for screening anxiolytic activity. Psychopharmacology 136, 291-298.

Blanchard, D.C., Shepherd, J.K., De Padua Carobrez, A., Blanchard, R.J., 1991a. Sex effects in defensive behavior: baseline differences and drug interactions. Neurosci. Biobehav. Rev. 15, 461-468.
Blanchard, D.C., Weatherspoon, A., Shepherd, J., Rodgers, R.J., Weiss, S.M., Blanchard, R.J., 1991b. 'Paradoxical' effects of morphine on antipredator defence reactions in wild and laboratory rats. Pharmacol. Biochem. Behav. 40, 819-828.

Blanchard, R.J., Agullana, R., McGee, L., Weiss, S., Blanchard, D.C., 1992. Sex differences in the incidence and sonographic characteritics of antipredator ultrasonic cries in the laboratory rat (Rattus norvegicus). J. Comp. Psychol. 106, 270-277.

Blumstein, L.K., Crawley, J.N., 1983. Further characterization of a simple, automated exploratory model for the anxiolytic effects of benzodiazepines. Pharmacol. Biochem. Behav. 18, 37-40.

Bourin, M., Hascoët, M., 2003. The mouse light/dark box test. Eur. J. Pharmacol. 463, 55-65.

Breslau, N., Schulz, L., Petersen, E., 1995. Sex differences in depression: A role for preexisting anxiety. Psychiat. Res. 58, 1-12.

Campbell, C.S., Finkelstein, J.S., Turek, F.W., 1978. The interaction of photoperiod and testosterone on the development of copulatory behaviour in castrated male hamsters. Physiol. Behav. 21, 409-415.

Cohen-Parsons, M., Carter, C.S., 1987. Males increase serum estrogen and estrogen receptor binding in brain of female voles. Physiol. Behav. 39, 309-314.

Cohen-Parsons, M., Carter, C.S., 1988. Males increase progestin receptor binding in brain of female voles. Physiol. Behav. 42, 191-197.

Costall, B., Jones, B.J., Kelly, M.E., Naylor, R.J., Tomkins, D.M., 1989. Exploration of mice in a black and white box: validation as a model of anxiety. Pharmacol. Biochem. Behav. 32, 777-785.

Crawley, J.N., 1981. Neuropharmacologic specificity of a simple animal model for the behavioral actions of benzodiazepines. Pharmacol. Biochem. Behav. 15, 695-699.

Crawley, J.N., 1985. Exploratory behavior models of anxiety in mice. Neurosci. Biobehav. Rev. 9, 37-44.

Crawley, J.N., Goodwin, F.K., 1980. Preliminary report of a simple animal behavior model for the anxiolytic effects of benzodiazepines. Pharmacol. Biochem. Behav. 13, 167-170.

Dobly, A., 2001. Movement patterns of male common voles (Microtus arvalis) in a network of $Y$ junctions: role of distant visual cues and scent marks. Can. J. Zool. 79, 2228-2238.

Elton, C., 1939. On the nature of cover. J. Wildlife Manage. 3, 332-338.

Frye, C.A., Petralia, S.M., Rhodes, M.E., 2000. Estrous cycle and sex differences in performance on anxiety tasks coincide with increases in hippocampal progesterone and $3 \alpha, 5 \alpha$-THP. Pharmacol. Biochem. Behav. 67, 587-596.

Galea, L.A.M., Kavaliers, M., Ossenkopp, K.-P., Hampson, E., 1995. Gonadal hormone levels and spatial learning performance in the Morris water maze in male and female meadow voles, Microtus pennsylvanicus. Horm. Behav. 29, 106-125.

Guo, M., Wu, C.F., Liu, W., Yang, J.Y., Chen, D., 2004. Sex difference in psychological behavior changes induced by longterm social isolation in mice. Prog. Neuro-Psychopharm. Biol. Psychiat. 28, 115-121.

Harestad, A.S., Shackleton, D.M., 1990. Cover and use of travel routes by female Townsend's voles in a laboratory arena. Biol. Behav. 15, 196-204.

Hascoët, M., Bourin, M., 1998. A new approach to the light/dark test procedure in mice. Pharmacol. Biochem. Behav. 60, 645-653.

Hendrie, C.A., Eilam, D., Weiss, S.M., 1997. Effects of diazepam and buspirone on the behavior of wild voles (Microtus socialis) in two models of anxiety. Pharmacol. Biochem. Behav. 58, 573-576. 
Imhof, J.T., Coelho, Z.M., Schmitt, M.L., Morato, G.S., Carobrez, A.P., 1993. Influence of gender and age on performance of rats in the elevated plus maze apparatus. Behav. Brain. Res. 56, 177-180.

Jacob, J., Brown, J.S., 2000. Microhabitat use, giving-up densities and temporal activity as short- and long-term antipredator behaviors in common voles. Oikos 91, 131-138.

Jacob, J., Hempel, N., 2003. Effects of farming practices on spatial behavior of common voles. J. Ethol. 21, 45-50.

Johnston, A.L., File, S.E., 1991. Sex differences in animal tests of anxiety. Physiol. Behav. 49, 245-250.

Kotler, B.P., 1984. Risk of predation and the structure of desert rodent communities. Ecology 65, 689-701.

Lee, C., Horvath, D.J., Metcalfe, R.W., Inskeep, E.K., 1970. Ovulation in Microtus pennsylvanicus in a laboratory environment. Lab. Anim. Care 20, 1098-1102.

Marcondes, F.K., Miguel, K.J., Melo, L.L., SpadariBratfisch, R.C., 2001. Estrous cycle influences the response of female rats in the elevated pluz-maze test. Physiol. Behav. 74, 435-440.

McCravy, K.W., Rose, R.K., 1992. An analysis of external features as predictors of reproductive status in small mammals. J. Mammol. 73, 151-159.

McQuade, R., Creton, D., Stanford, S.C., 1999. Effect of novel environmental stimuli on rat behavior and central noradrenaline funciton measured by in vivo microdialysis. Psychopharmacology 145, 393-400.

Misslin, R., Belzung, C., Vogel, E., 1989. Behavioral validation of a light/dark choice procedure for testing anti-anxiety agents. Behav. Proc. 18, 119-132.

Mora, S., Dussaubat, N., Diaz-Veliz, G., 1996. Effects of the estrous cycle and ovarian hormones on the behavioral indices of anxiety in female rats. Psychoneuroendocrinology 21, 609-620.

Morgan, M.A., Pfaff, D.W., 2001. Effects of estrogen on activity and fear-related behaviors in mice. Horm. Behav. 40, 472-482.

Morgan, M.A., Pfaff, D.W., 2002. Estrogen's effects on activity, anxiety, and fear in two mouse strains. Behav. Brain. Res. 132, 85-93.

Morgan, M.A., Schulkin, J., Pfaff, D.W., 2004. Estrogens and nonreproductive behaviors related to activity and fear. Neurosci. Biobehav. Rev. 28, 55-63.

Nasello, A.G., Machado, C., Bastos, J.F., Felicio, L.F., 1998. Sudden darkness induces a high activity-low anxiety state in male and female rats. Physiol. Behav. 63, 451-454.

Norrdahl, K., Korpimaki, E., 1998. Does mobility or sex of voles affect risk of predation by mammalian predators? Ecology 79, 226-232.

Ossenkopp, K.-P., Kavaliers, M., 1996. Measuring spontaneous locomotor activity in small mammals. In: Ossenkopp, K.-P., Kavaliers, M., Sanberg, P.R. (Eds.), Measuring Movement And Locomotion: From Invertebrates to Humans. Springer, Berlin, pp. 33-51.

Ossenkopp, K.-P., Mazmanian, D.S., 1985. The measurement and integration of behavioral variables: aggregation and complexity as important issues. Neurobehav. Toxicol. Teratol. 7, 95-100.
Ossenkopp, K.-P., Sorensen, L., Mazmanian, D.S., 1994. Factor analysis of open-field behaviour in the rat (Rattus norvegicus): application of the three-way PARAFAC model to a longitudinal data set. Behav. Process. 31, 129-144.

Palanza, P., 2001. Animal models of anxiety and depression: how are females different? Neurosci. Biobehav. Rev. 25, 219-233.

Perrot-Sinal, T.S., Heale, V.R., Ossenkopp, K.-P., Kavaliers, M., 1996. Sexually dimorphic aspects of spontaneous activity in meadow voles (Microtus pennsylvanicus): effects of exposure to fox odor. Behav. Neurosci. 110, 1126-1132.

Perrot-Sinal, T.S., Innes, D., Kavaliers, M., Ossenkopp, K.-P., 1998. Plasma testosterone levels are related to various aspects of locomotor activity in wild-caught male meadow voles (Microtus pennsylvanicus). Physiol. Behav. 64, 31-36.

Perrot-Sinal, T.S., Ossenkopp, K.-P., Kavliers, M., 1999. Effects of repeated exposure to fox odor on locomotor activity levels and spatial movement patterns in breeding male and female meadow voles (Microtus pennsylvanicus). J. Chem. Ecol. 25, 1567-1584.

Perrot-Sinal, T.S., Ossenkopp, K.-P., Kavaliers, M., 2000. Influence of a natural stressor (predator odor) on locomotor activity in the meadow vole (Microtus pennsylvanicus): modulation by sex, reproductive condition and gonadal hormones. Psychoneuroendocrinology 25, 259-276.

Pigott, T.A., 1999. Gender differences in the epidemiology and treatment of anxiety disorders. J. Clin. Psychiatry 60, 4-15.

Prendergast, B.J., Nelson, R.J., Zucker, I., 2002. Mammalian seasonal rhythms: behavior and neuroendocrine substrates. In: Pfaff, D.W. (Ed.), Hormones, Brain, and Behavior. Academic Press, San Diego.

Rowsemitt, C.N., 1986. Seasonal variations in activity rhythms of male voles: mediation by gonadal hormones. Physiol. Behav. 37, 797-803.

Seabloom, R.W., 1985. Biology of new world Microtus. In: Tamarin, R.H. (Ed.), Special Publication No. 8. American Society of Mammologists, Boston, pp. 685-718.

Travers, S.E., Kaufman, D.W., Kaufman, G.A., 1988. Differential use of experimental habitat patches by foraging Peromyscus maniculatus on dark and bright nights. J. Mammol. 69, 869872.

Treit, D., 1985. Animal models for the study of anti-anxiety agents: a review. Neurosci. Biobehav. Rev. 9, 203-222.

Treit, D., Fundytus, M., 1989. Thigmotaxis as a test for anxiolytic activity in rats. Pharmacol. Biochem. Behav. 31, 959-962.

Turek, F., Elliott, J., Alvis, J., Menaker, M., 1975. The interaction of castration and photoperiod in the regulation of hypophyseal and serum gonadotropin levels in male golden hamsters. Endocrinology 96, 854-860.

Voikar, V., Koks, S., Vasar, E., Rauvala, H., 2001. Strain and gender differences in the behavior of mouse lines commonly used in transgenic studies. Physiol. Behav. 72, 271-281.

Walsh, R.N., Cummins, R.A., 1976. The open-field test: a critical review. Psychol. Bull. 83, 482-504.

Zimmerberg, B., Farley, M.J., 1993. Sex differences in anxiety behavior in rats: role of gonadal hormones. Physiol. Behav. 54, 1119-1124.

Available online at www.sciencedirect.com

science 